\title{
Streptomyces smaragdinus sp. nov., isolated from the gut of the fungus growing-termite Macrotermes natalensis
}

\author{
Jan W. Schwitalla'†, René Benndorf ${ }^{1}$, Karin Martin 1,*, John Vollmers², Anne-Kristin Kaster², Z. Wilhelm de Beer ${ }^{3}$, \\ Michael Poulsen ${ }^{4}$ and Christine Beemelmanns ${ }^{1, *}$
}

\begin{abstract}
The taxonomic position of a novel aerobic, Gram-positive actinobacteria, designated strain $\mathrm{RB}^{\top}$, was determined using a polyphasic approach. The strain, isolated from the gut of the fungus-farming termite Macrotermes natalensis, showed morphological, physiological and chemotaxonomic properties typical of the genus Streptomyces. Based on 16S rRNA gene sequence analysis, the closest phylogenetic neighbour of $\mathrm{RB}^{\top}$ was Streptomyces polyrhachis DSM 42102 ${ }^{\top}$ (98.87\%). DNA-DNA hybridization experiments between strain RB5 ${ }^{\top}$ and S. polyrhachis DSM $42102^{\top}$ resulted in a value of $27.4 \%(26.8 \%)$. The cell wall of strain RB5 ${ }^{\top}$ contained LL-diaminopimelic acid as the diagnostic amino acid. Mycolic acids and diagnostic sugars in whole-cell hydrolysates were not detected. The strain produced the following major phospholipids: diphosphatidylglycerol, phosphatidylethanolamine, phosphatidylinositol, phosphatidylinositol-mannoside and phosphatidylserine. The menaquinone profile showed hexa- and octahydrogenated menaquinones containing nine isoprene units [MK-9( $\left.\mathrm{H}_{6}\right)$ and $\left.M K-9\left(\mathrm{H}_{8}\right)\right]$. The strain exhibited a fatty acid profile containing the following major fatty acids: 12-methyltridecanoic acid (iso- $\mathrm{C}_{14: 0}$ ) 12-methyltetradecanoic acid (anteiso- $\mathrm{C}_{15: 0}$ ), 13-methyltetradecanoic acid (iso- $\mathrm{C}_{15: 0}$ ) and 14-methylpentadecanoic acid (iso- $\mathrm{C}_{16: 0}$ ). Here, we propose a novel species of the genus Streptomyces - Streptomyces smaragdinus with the type strain RB5 ${ }^{\top}$ (=VKM Ac-2839 $=$ NRRL B65539').
\end{abstract}

\section{INTRODUCTION}

The class Actinobacteria harbours numerous genera including the well-known genus Streptomyces, which was first introduced by Waksman and Henrici [1]. Streptomyces species are characterized as aerobic, Gram-positive, filamentous bacteria, which form branched substrate mycelium and aerial hyphae. Members of the genus have a high $\mathrm{G}+\mathrm{C}$ content and contain the diagnostic LL-diaminopimelic acid in the cell-wall peptidoglycan $[2,3]$. In addition to being reported as typical soil bacteria, members of the genus Streptomyces have also been found to act as protective symbionts for different insect species [4-6]. Research efforts into the chemical ecology of Streptomyces have also been stimulated by the fact that the genus is known for its enormous biosynthetic and metabolic capability to produce small bioactive molecules [7, 8]. In this study, we focused on the isolation and characterization of culturable microbes from fungus-growing termites of the genus Macrotermes natalensis. Preceding microbiome studies indicated a highly diverse, but stable microbiome within the termite gut and fungus comb of the termite nest $[9,10]$. In particular, comb analysis revealed a strong abundance of members of the phyla Firmicutes, Bacteroidetes, Proteobacteria and Actinobacteria, with Streptomyces as one of the most dominant genera of the latter. Here, we speculated that the specialized symbiotic ecosystem also represents an unexplored source of new bacterial species that assist in the breakdown of organic material to sustain growth of the termite colony. Using a cultivation-based approach, we

Author affiliations: 'Leibniz Institute for Natural Product Research and Infection Biology e. V., Hans-Knöll-Institute, Beutenbergstraße 11 a, 07745 Jena, Germany; ${ }^{2}$ Institute for Biological Interfaces (IBG 5), Karlsruhe Institute of Technology, Hermann-von-Helmholtz-Platz 1, 76344 EggensteinLeopoldshafen, Germany; ${ }^{3}$ Department of Microbiology and Plant Pathology, Forestry and Agriculture Biotechnology Institute, University of Pretoria, 0028 Hatfield, South Africa; “University of Copenhagen, Department of Biology, Section for Ecology and Evolution, Universitetsparken 15, 2100 Copenhagen East, Denmark.

*Correspondence: Karin Martin, karin.martin@leibniz-hki.de; Christine Beemelmanns, christine.beemelmanns@leibniz-hki.de Keywords: Macrotermes natalensis; Streptomyces; termite gut.

Abbreviations: DDH, DNA-DNA hybridization; ISP, International Streptomyces Project.

The GenBank/EMBL accession number for the partial 16S rRNA gene sequence of strain RB5 ${ }^{\top}$ is KY558696.2. This Whole Genome Shotgun project has been deposited at DDBJ/ENA/GenBank under the accession WEGJ00000000. The version described in this paper is WEGJ01000000.1.

tThese authors contributed equally to this work

Three supplementary figures and five supplementary tables are available with the online version of this article. 004478 @ 2020 The Authors 
isolated and characterized a novel strain, $\mathrm{RB} 5^{\mathrm{T}}$, comprising a new species of the genus Streptomyces, hereafter named as Streptomyces smaragdinus.

\section{ISOLATION AND ECOLOGY}

In February 2015 symbiotic actinomycetes associated with fungus-growing termites of the genus Macrotermes natalensis

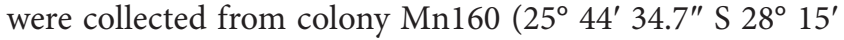
38.7" E, Pretoria, South Africa) and strain $\mathrm{RB}^{\mathrm{T}}$ was isolated from the guts of termite workers [11]. Colonies growing on chitin agar supplemented with $0.05 \mathrm{~g} \mathrm{l}^{-1}$ cycloheximide were transferred onto yeast extract-malt extract agar (ISP2). Isolated pure strain $\mathrm{RB}^{\mathrm{T}}$ was maintained on ISP 2 at $30^{\circ} \mathrm{C}$ and as glycerol suspensions $(25 \%, \mathrm{v} / \mathrm{v})$ at $-80^{\circ} \mathrm{C}$.

\section{PHYLOGENY}

Extraction of genomic DNA and PCR amplification of the $16 \mathrm{~S}$ rRNA gene of $\mathrm{RB}^{\mathrm{T}}$ was performed as described previously [11]. Furthermore, the sequence for the 16S rRNA gene of $\mathrm{RB}^{\mathrm{T}}$ was extracted from whole genome data using Artemis [12] and the near-complete $16 \mathrm{~S}$ rRNA gene sequence was used for phylogenetic analyses. BLASTn analysis was performed using the NCBI database. The results indicated that strain $\mathrm{RB}^{\mathrm{T}}$ is a member of the genus Streptomyces. The 16S rRNA gene sequences of published Streptomyces reference strains were downloaded from the NCBI 'refseq' database [13] and pairwise sequence similarities were calculated using the method recommended by Meier-Kolthoff et al. [14] on the GGDC web server [15]. sINA sequence alignment was used for $16 \mathrm{~S}$ rRNA gene sequence alignments [16]. Phylogenetic trees were reconstructed with MEGA software (version 7.0.26) [17] using the neighbour-joining [18] and maximum-likelihood algorithms [19]. The evolutionary distance model of Tamura [20] was used to generate evolutionary distance matrices for the maximum-likelihood and neighbour-joining algorithms with deletion of complete gaps and missing data. For the maximum-likelihood algorithm, discrete gamma distribution was used $(+G)$ and the rate variation model allowed for some sites to be evolutionarily invariable $(+I)$. For the neighbour-joining algorithm, rate variation among sites was modelled with a gamma distribution. The confidence values of nodes were evaluated by bootstrap analysis based on 1000 re-samplings [21].

Strain $\mathrm{RB}^{\mathrm{T}}$ showed highest $16 \mathrm{~S}$ rRNA similarity to Streptomyces polyrhachis DSM $42102^{\mathrm{T}}$ (=NEAU-ycm ${ }^{\mathrm{T}}$; $\left.98.87 \%\right)$. Lower levels of $16 \mathrm{~S}$ rRNA gene sequence similarity $(<98.70 \%)$ were found to all other Streptomyces type strains (Table S1, available in the online version of this article).

Phylogenetic analysis based on the 16S rRNA gene showed that strain $\mathrm{RB} 5^{\mathrm{T}}$ formed a distinct branch with S. polyrhachis DSM $42101^{\mathrm{T}}$ in the neighbour-joining tree (Fig. 1) and the topology structure was also supported by the maximumlikelihood tree (Fig. S1). These findings are supported by high bootstrap values of $90 \%$ in both trees.

\section{GENOME FEATURES}

Genome sequencing of $\mathrm{RB}^{\mathrm{T}}$ was performed as previously described and the $\mathrm{G}+\mathrm{C}$ content of the DNA was determined from whole sequence data [11]. DNA-DNA hybridization (DDH) was performed by the German Collection of Microorganisms and Cell Cultures GmbH (DSMZ) Identification service as a classical wet-lab experiment. The required DNA was obtained as described by Cashion et al. [22] and DDH experiments were performed in duplicate according to the methods of De Ley et al. [23] and Huss et al. [24].

The wet-lab DDH value of $\mathrm{RB}^{\mathrm{T}}$ and the closest relative S. polyrhachis DSM $42102^{\mathrm{T}}$ was $27.4 \%(26.8 \%)$. This value is below the threshold value of $70 \%$ for the delineation of bacterial species recommended by Meier-Kolthoff et al. [14] and Wayne et al. [25].

The genome of RB5 ${ }^{\mathrm{T}}$ was $7.9 \mathrm{Mb}$ in size (107 contigs with an N50 value of $161565 \mathrm{bp}$ and an L50 value of 13, total CDS were 7136 and the genome had a completeness of $100 \%$ (Table S2). The $\mathrm{G}+\mathrm{C}$ content of the type strain was determined as $72 \mathrm{~mol} \%$, which is typical for the genus of Streptomyces $[26,27]$.

\section{PHYSIOLOGY AND CHEMOTAXONOMY}

Morphological characteristics of the strains were determined on cultures grown for $5-14$ days on ISP2 agar at $30^{\circ} \mathrm{C}$ using a light microscope (Imager M2, Carl Zeiss $\mathrm{GmbH}$ ) and a field emission scanning electron microscope. Scanning electron microscopy was performed as described by Groth et al. [28]. Culture characteristics were determined using different ISP media as described by Shirling and Gottlieb [29] and similar to the approach described by Wink et al. [30]. Colony colour was determined using Baumann's Farbatlas 1 (Paul Baumann/ Aue). Carbohydrate utilization was determined using ISP9 (carbon utilization medium), supplemented with $1 \%$ sole carbon source, as positive control served ISP9 supplemented with $1 \%$ glucose. Melanoid pigment production was examined on peptone-yeast extract iron agar (ISP6), tyrosine agar (ISP7) and a synthetic medium from Suter [31] with and without tyrosine $\left(1 \mathrm{~g} \mathrm{l}^{-1}\right)$. Sodium chloride tolerance was tested on ISP2 with concentrations from $1-15 \%$ and $\mathrm{pH}$ tolerance (range, $\mathrm{pH} 4-10$ ) was tested in ISP2 broth using the buffer system described by Xu et al. [32]. Gram-staining was performed according to the standard method [33]. Decomposition of purines, tyrosine and organic acids was tested using the method described by Gordon et al. [34]. Antibiotic susceptibility was tested on ISP2 agar [35]. Antibiotics were purchased from Bio-Rad, bioMérieux, Difco, BD and $\mathrm{BBL}$. Anaerobic and microaerophilic growth was tested by cultivating the strains at $28^{\circ} \mathrm{C}$ in chambers with anaerobic or microaerophilic atmosphere generated by GENbox anaerob or GENbox microaer (bioMérieux cat. nos. 96124 and 96125).

For chemotaxonomic analyses, freeze-dried cells were obtained from culture grown in liquid ISP2 medium for 3 days at $28^{\circ} \mathrm{C}$ on a rotary shaker at 180 r.p.m. The diagnostic diamino acid of the cell wall was determined in whole-cell hydrolysates 


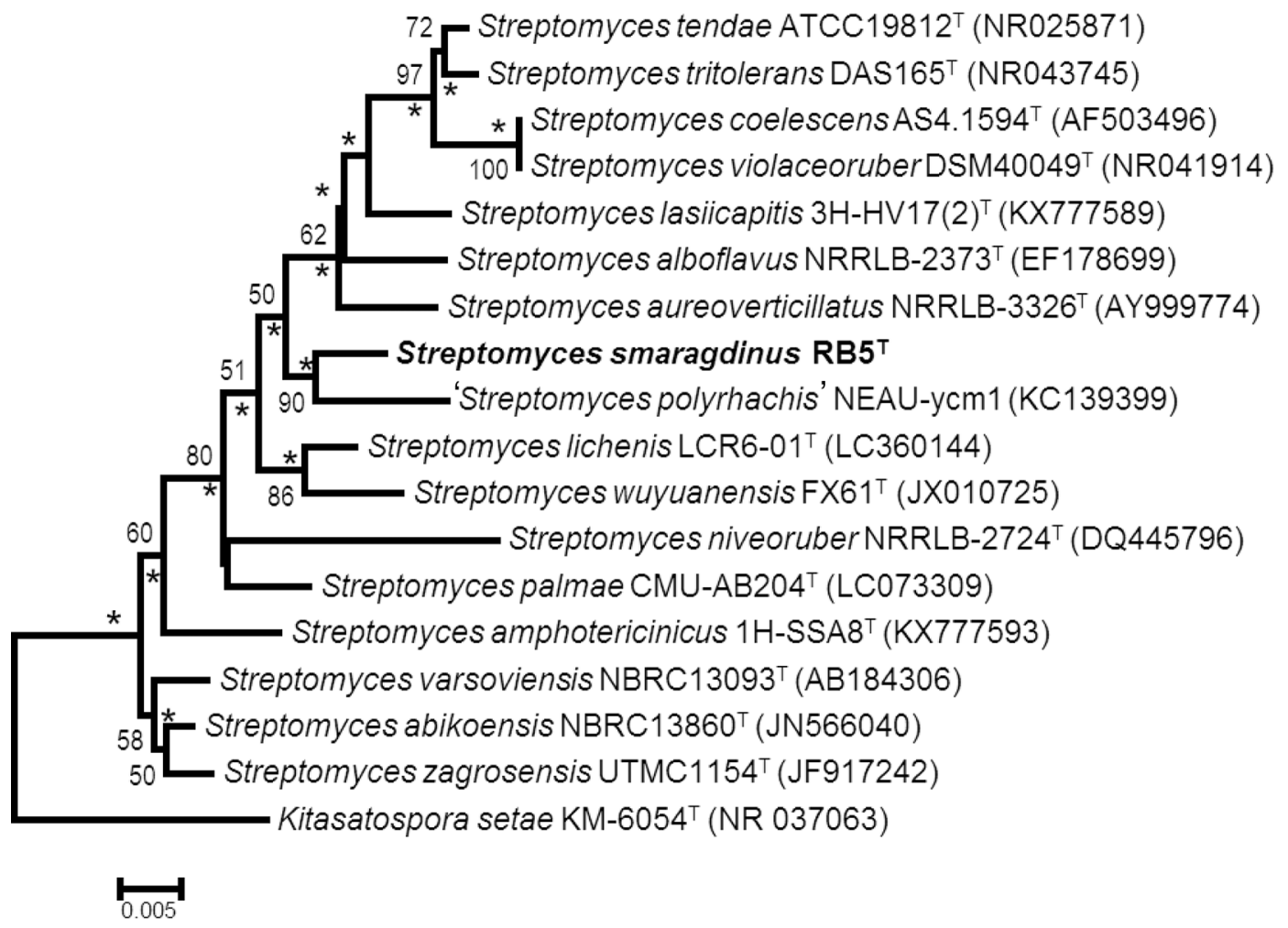

Fig. 1. Neighbour-joining tree based on almost-complete $16 \mathrm{~S}$ rRNA gene sequences showing relationships between strain RB5 ${ }^{\top}$ and species of the genus Streptomyces. Kitasatospora setae KM-6054 ${ }^{\top}$ was used as an outgroup. Asterisks donate branches that were also recovered in the maximum-likelihood tree. Only bootstrap values above 50\% (percentages of 1000 pseudo-replications) are shown. Bar, 0.005 substitutions per nucleotide position.

by paper chromatography according to Hasegawa [36]. Whole-cell sugars were examined according to Schumann [37]. The occurrence of mycolic acids was detected by TLC as described by Minnikin et al. [38]. Respiratory quinones of the strains were extracted, purified and identified as described by Collins et al. [39] and Wink et al. [40]. Polar lipids were extracted by the method of Minnikin et al. [41] and identified by two-dimensional thin-layer chromatography as described by Collins et al. [42]. Extraction and analysis of fatty acids was done by the DSMZ Identification service by described standard methods [43].

Strain $\mathrm{RB}^{\mathrm{T}}$ showed good growth on all tested media and differentiating phenotypic characteristics are shown in Table 1 (Fig. S2, Table S3). White aerial mycelium was well developed on ISP2 and ISP6, poorly developed on ISP5, and no aerial mycelium occurred on ISP1, ISP3, ISP4, ISP7 and Suter medium. Substrate mycelium was well developed on all media with an average hyphal diameter of $0.7-1.1 \mu \mathrm{m}$. The substrate mycelium was light green (ISP1-ISP5, ISP7), dark green (ISP6) to beige (Suter Medium). Sporulation was not observed on the tested media (Fig. 2). Phenotypic characterization revealed that strain $\mathrm{RB}^{\mathrm{T}}$ grew at $\mathrm{pH}$ 6-8 (optimum, $\mathrm{pH} 7.0)$ and at $0-1 \%(\mathrm{w} / \mathrm{v}) \mathrm{NaCl}$ (optimum, $0-1 \%)$. Strain $\mathrm{RB}^{\mathrm{T}}$ grew well at $20-37^{\circ} \mathrm{C}$ and weak growth was observed at 15 and $45^{\circ} \mathrm{C}$. Optimal growth temperature was $28^{\circ} \mathrm{C}$.
Decomposition of malate, pyruvate and hypoxanthine was detected. The strain showed only resistance against penicillin G (Table S4).

Whole-cell hydrolysates of strain $\mathrm{RB}^{\mathrm{T}}$ contained LLdiaminopimelic acid; diagnostic sugars and mycolic acids in whole-cell hydrolysates were not detected. The menaquinone profile of RB5 ${ }^{\mathrm{T}}$ consisted of MK-9 $\left(\mathrm{H}_{6}\right), \mathrm{MK}-9\left(\mathrm{H}_{8}\right)$ and traces MK- $9\left(\mathrm{H}_{4}\right)$ in a ratio of 49:25:5 whereas $S$. polyrhachis DSM42102 exhibited MK-9 $\left(\mathrm{H}_{6}\right)$, and MK-9 $\left(\mathrm{H}_{8}\right)$ and MK-9 $\left(\mathrm{H}_{4}\right)$ in a ratio of 55:30:15. The polar lipid profile of $\mathrm{RB}^{\mathrm{T}}$ consisted of the major compounds diphosphatidylglycerol, phosphatidylethanolamine, phosphatidylinositol, phosphatidylserine, phosphatidylinositol-mannoside, an unidentified glycolipid, an unidentified aminophospholipid and six unidentified phospholipids (PL1-PL6), an aminolipid (AL1) and an unidentified lipid (L1) (Fig. S3).

The fatty acid profile of strain $\mathrm{RB}^{\mathrm{T}}{ }^{\text {(Table }} 4$ ) was composed of the major fatty acids anteiso- $\mathrm{C}_{15: 0}(44.8 \%)$, iso- $\mathrm{C}_{16: 0}(19.4 \%)$, iso- $\mathrm{C}_{14: 0}(13.0 \%)$ and $\mathrm{C}_{15: 0}(6.6 \%)$. In contrast, the fatty acid profiles of the closest relative S. polyrhachis DSM $42102^{\mathrm{T}}$ contain lower amounts of anteiso- $\mathrm{C}_{15: 0}(21.9 \%)$ and iso- $\mathrm{C}_{14: 0}$ $(11.2 \%)$. Higher amounts of iso- $\mathrm{C}_{16: 0}^{15: 0}(38.9 \%)$, anteiso- $\mathrm{C}_{17: 0}$ (8.4\%) and iso- $\mathrm{C}_{16: 1} \omega 6 \mathrm{c}(7.1 \%)$ were detected in S. polyrhachis DSM $42102^{\mathrm{T}}$ (Table S5). 
Table 1. Physiological properties that separate the strain $\mathrm{RB}^{\top}$ from the type strain of phylogenetically closest related Streptomyces species Streptomyces polyrhachis DSM $42102^{\top}$

Strains: 1, RB5 ${ }^{\top} ; 2$, Streptomyces polyrhachis DSM 42102'. Utilization tests are analysed as follows: ++, grows better than positive control, +, grows like positive control (basal medium with glucose); (+), better than negative control but not like positive control; -, not better than negative control (basal medium with water). All strains were positive for utilization of D-glucose. Decomposition of purines, tyrosine and organic acids: -, no decomposition; $(+)$, weak decomposition; +, decomposition; ++, very good decomposition

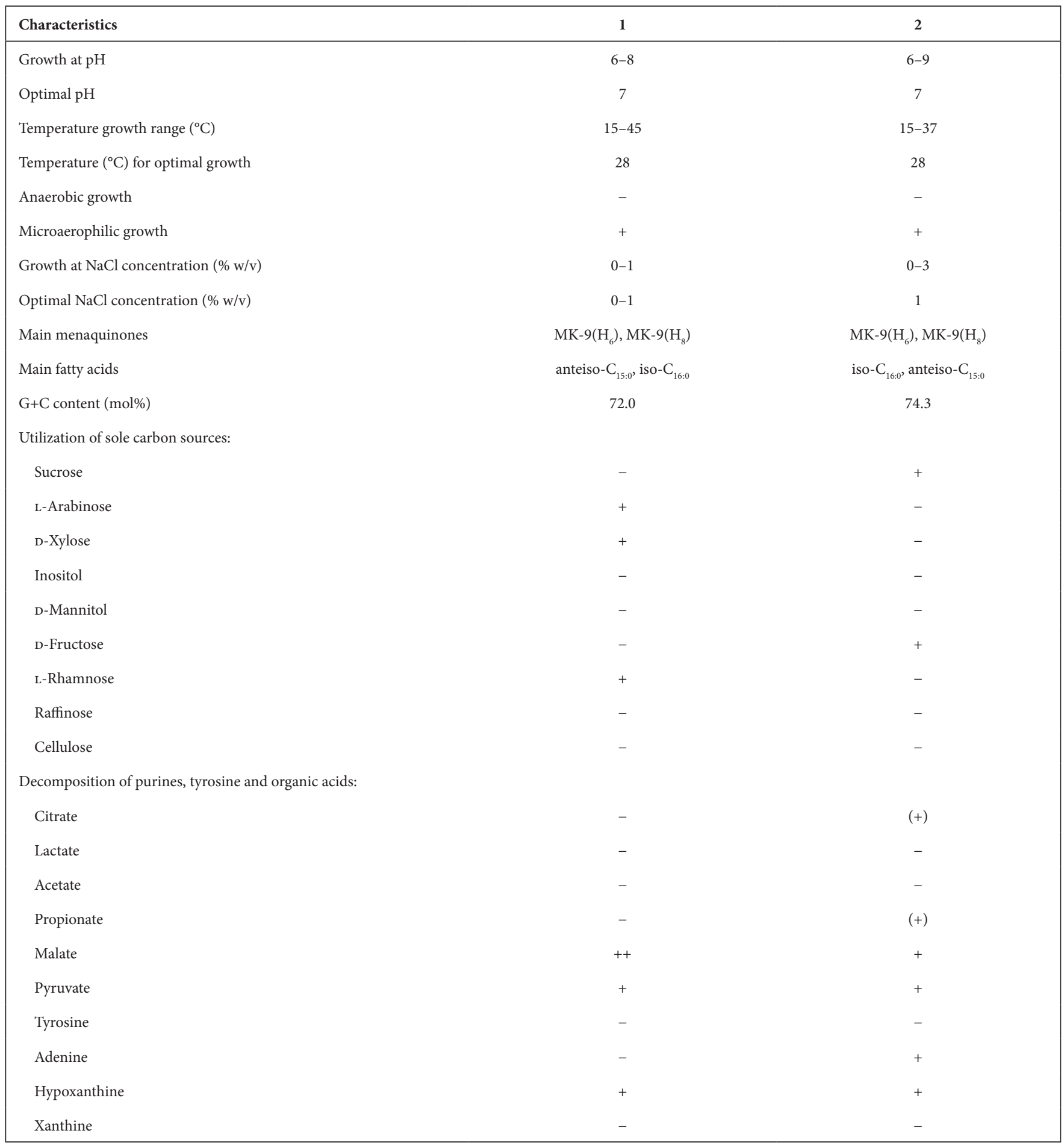




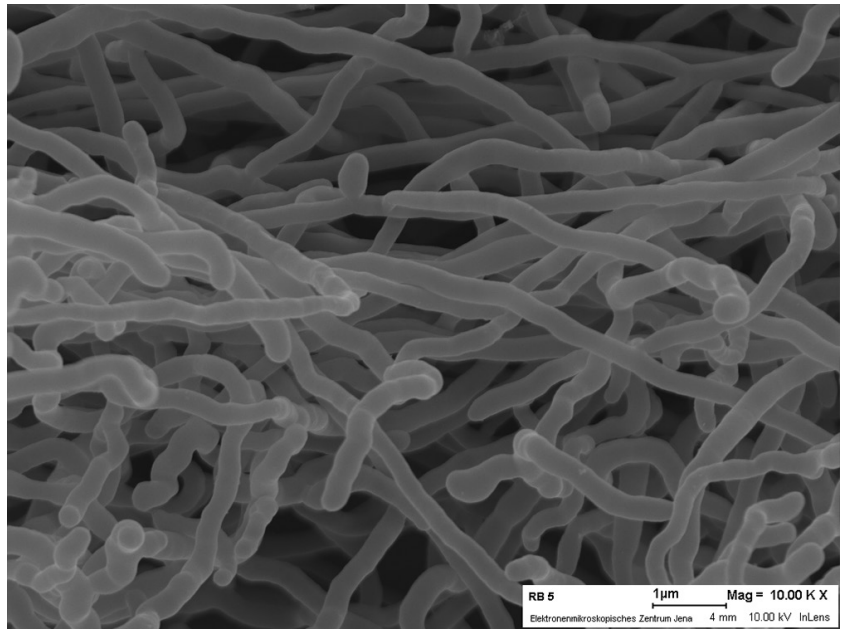

Fig. 2. Scanning electron micrograph of strain $\mathrm{RB}^{\top}{ }^{\mathrm{T}}$ (a) cultivated at $28^{\circ} \mathrm{C}$ on ISP2 agar for 14 days

The analyses of fatty acid profiles clearly differentiated the new isolate from its closest relative. Subsequent analyses of the culture characteristics of both strains supported this assumption.

Morphological, physiological, genetic and chemotaxonomic data support the delineation of $\mathrm{RB}^{\mathrm{T}}$ as representing a novel species of the genus Streptomyces.

\section{DESCRIPTION OF STREPTOMYCES SMARAGDINUS SP. NOV.}

Streptomyces smaragdinus (sma.rag.di'nus. L. masc. adj. smaragdinus, smaragd-green-coloured, referring to the smaragdgreen-coloured substrate mycelium on ISP2 and ISP6 media).

Aerobic, Gram-stain-positive actinobacterium that forms branched, vegetative mycelium. Good growth occurs on ISP1ISP7 and Suter medium with an average hyphal diameter of $0.7-1.1 \mu \mathrm{m}$. Aerial mycelium is forms poorly on ISP2, ISP5 and ISP6 within 12-14 days. A dark green colour is observed on ISP6. Spore formation is not detectable on ISP1-ISP7 or Suter medium.

The $\mathrm{pH}$ range for growth is $\mathrm{pH}$ 6-8 (optimum, $\mathrm{pH}$ 7.0). The maximum concentration of $\mathrm{NaCl}$ for growth is $1 \%(\mathrm{w} / \mathrm{v})$ supplemented on ISP2. Growth occurs between $15-45^{\circ} \mathrm{C}$ on ISP2 agar with an optimum at $28^{\circ} \mathrm{C}$. The strain grows with glucose, L-arabinose, $\mathrm{D}$-xylose and L-rhamnose as a sole carbon source, but not with sucrose, inositol, mannitol, fructose, raffinose or cellulose. Malate, pyruvate and hypoxanthine are decomposed. The strain is resistant to penicillin G.

The diagnostic amino acid of the peptidoglycan is LLdiaminopimelic acid. Mycolic acids and diagnostic sugars in whole-cell hydrolysates are not detected. The major polar lipids are diphosphatidylglycerol, phosphatidylethanolamine, phosphatidylinositol, phosphatidylserine, phosphatidylinositol-mannoside, an unidentified glycolipid, an unidentified aminophospholipid, six unidentified phospholipids, an unidentified aminolipid and the unidentified lipid L1. The major fatty acids are anteiso- $\mathrm{C}_{15: 0}$ (12-methyltetradecanoic acid), iso- $\mathrm{C}_{16: 0}$ (iso-hexadecanoic acid), iso- $\mathrm{C}_{14: 0}$ (isomyristic acid) and $\mathrm{C}_{15: 0}$ (pentadecanoic acid). The predominant menaquinones are MK-9 $\left(\mathrm{H}_{6}\right)$ and MK- $9\left(\mathrm{H}_{8}\right)$. The DNA G+C content of the type strain is $72 \mathrm{~mol} \%$.

The type strain, $\mathrm{RB}^{\mathrm{T}}\left(=\mathrm{VKM}\right.$ Ac- $\left.2839^{\mathrm{T}}=\mathrm{NRRL} \mathrm{B}-65539^{\mathrm{T}}\right)$, was isolated from the gut of the termite Macrotermes natalensis (major worker). The GenBank/EMBL accession number for the partial $16 \mathrm{~S}$ rRNA gene sequence of strain $\mathrm{RB}^{\mathrm{T}}$ is KY558696.2. This Whole Genome Shotgun project has been deposited at DDBJ/ENA/GenBank under the accession WEGJ00000000 (Bio Project PRJNA545686;; Bio Sample SAMN11898449). The version described in this paper is WEGJ01000000.

\section{Funding information}

J.S and R.B. were funded by the International Leibniz Research School for Microbial and Biomolecular Interactions (ILRS). Furthermore, R.B. was funded by the Jena School for Microbial Communication (JSMC, DFG). Financial support from the Boehringer Ingelheim Foundation, the Daimler Benz foundation, the Deutsche Forschungsgemeinschaft (DFG, German Science Foundation; (BE 4799/3-1, SFB 1127/2 ChemBioSys 239748522 and BE-4799/3-1) to C.B. and the Villum Kann Rasmussen foundation for a Young Investigator Fellowship (VKR10101) to M.P. is greatly acknowledged.

\section{Acknowledgements}

We thank the Oerlemans family (Mookgophong) for permission to sample colonies at their farm. We thank Susanne Linde (Elektronenmikroskopisches Zentrum FSU Jena) for electron microscopy pictures.

\section{Conflicts of interest}

The authors declare that there are no conflicts of interest.

\section{References}

1. Waksman SA, Henrici AT. The nomenclature and classification of the actinomycetes. J Bacteriol 1943;46:337-PMCID.

2. Lechevalier MP, Lechevalier H. Chemical composition as a criterion in the classification of aerobic actinomycetes. Int J Syst Bacteriol 1970;20:435-443.

3. van der Meij A, Worsley SF, Hutchings MI, van Wezel GP. Chemical ecology of antibiotic production by actinomycetes. FEMS Microbiol Rev 2017:41:392-416.

4. Van Arnam EB, Currie CR, Clardy J. Defense contracts: molecular protection in insect-microbe symbioses. Chem Soc Rev 2018:47:1638-1651.

5. Ramadhar TR, Beemelmanns C, Currie CR, Clardy J. Bacterial symbionts in agricultural systems provide a strategic source for antibiotic discovery. J Antibiot 2014;67:53-58.

6. Chevrette MG, Carlson CM, Ortega HE, Thomas C, Ananiev GE et al. The antimicrobial potential of Streptomyces from insect microbiomes. Nat Commun 2019;10:516

7. Newman DJ, Cragg GM. Natural products as sources of new drugs over the 30 years from 1981 to 2010. J Nat Prod 2012;75:311-335.

8. Katz L, Baltz RH. Natural product discovery: past, present, and future. J Ind Microbiol Biotechnol 2016;43:155-176. 
9. Otani S, Mikaelyan A, Nobre T, Hansen LH, Koné NA et al. Identifying the core microbial community in the gut of fungus-growing termites. Mol Ecol 2014;23:4631-4644.

10. Otani S, Hansen LH, Sørensen SJ, Poulsen M. Bacterial communities in termite fungus combs are comprised of consistent gut deposits and contributions from the environment. Microb Ecol 2016;71:207-220.

11. Benndorf R, Guo H, Sommerwerk E, Weigel C, Garcia-Altares M et al. Natural products from actinobacteria associated with fungusgrowing termites. Antibiotics 2018;7:83.

12. Rutherford K, Parkhill J, Crook J, Horsnell T, Rice $P$ et al. Artemis: sequence visualization and annotation. Bioinformatics 2000;16:944-945.

13. Pruitt KD, Tatusova T, Maglott DR. NCBI reference sequence (RefSeq): a curated non-redundant sequence database of genomes, transcripts and proteins. Nucleic Acids Res 2005;33:D501-D504.

14. Meier-Kolthoff JP, Göker M, Spröer C, Klenk HP. When should a $\mathrm{DDH}$ experiment be mandatory in microbial taxonomy? Arch Microbiol 2013;195:413-418.

15. GGDC. GGDC web server available from. http://ggdc.dsmz.de/

16. Pruesse E, Peplies J, Glöckner FO. SINA: Accurate high-throughput multiple sequence alignment of ribosomal RNA genes. Bioinformatics 2012;28:1823-1829.

17. Kumar S, Stecher G, Tamura K. MEGA7: molecular evolutionary genetics analysis version 7.0 for bigger datasets. Mol Biol Evol 2016;33:1870-1874.

18. Saitou N, Nei M. The neighbor-joining method: a new method for reconstructing phylogenetic trees. Mol Biol Evol 1987;4:406-425.

19. Felsenstein J. Evolutionary trees from DNA sequences: a maximum likelihood approach. J Mol Evol 1981;17:368-376.

20. Tamura K. Estimation of the number of nucleotide substitutions when there are strong transition-transversion and $\mathrm{G}+\mathrm{C}$-content biases. Mol Biol Evol 1992;9:678-687.

21. Felsenstein J. Confidence limits on phylogenies: an approach using the bootstrap. Evolution 1985;39:783-791.

22. Cashion P, Holder-Franklin MA, McCully J, Franklin M. A rapid method for the base ratio determination of bacterial DNA. Anal Biochem 1977;81:461-466.

23. De Ley J, Cattoir H, Reynaerts A. The quantitative measurement of DNA hybridization from renaturation rates. Eur $J$ Biochem 1970;12:133-142.

24. Huss VA, Festl H, Schleifer KH. Studies on the spectrophotometric determination of DNA hybridization from renaturation rates. Syst Appl Microbiol 1983;4:184-192.

25. Wayne LG, Moore WEC, Stackebrandt E, Kandler O, Colwell RR et al. Report of the ad hoc committee on reconciliation of approaches to bacterial systematics. Int J Syst Evol Microbiol 1987;37:463-464.

26. Harrison J, Studholme DJ. Recently published Streptomyces genome sequences. Microb Biotechnol 2014;7:373-380.

27. Kämpfer P. The family Streptomycetaceae, Part I: taxonomy. In: Dworkin M, Falkow S, Rosenberg E, Schleifer K-H, Stackebrandt E (editors). The Prokaryotes: Volume 3: Archaea Bacteria: Firmicutes, Actinomycetes. New York, NY: Springer New York; 2006. pp. 538-5604.
28. Groth I, Schumann P, Rajney FA, Martin K, Schuetze B et al. Bogoriella caseilytica gen. nov., sp. nov., a new alkaliphilic actinomycete from a soda lake in Africa. Int J Syst Bacteriol 1997:47:788-794.

29. Shirling EB, Gottlieb D. Methods for characterization of Streptomyces species. Int J Syst Bacteriol 1966;16:313-340.

30. Wink J, Kroppenstedt RM, Seibert G, Stackebrandt E. Actinomadura namibiensis sp. nov. Int J Syst Evol Microbiol 2003;53:721-724.

31. Suter MA. Isolierung und Charakterisierung von Melanin-negativen Mutanten aus Streptomyces glaucescens. Diss Naturwiss ETH Zürich, Nr 1978;6276:0000.

32. Xu P, Li WJ, Tang SK, Zhang YQ, Chen GZ et al. Naxibacter alkalitolerans gen. nov., sp. nov., a novel member of the family 'Oxalobacteraceae' isolated from China. Int J Syst Evol Microbiol 2005;55:1149-1153.

33. Kamlage B. Methods for general and molecular bacteriology. In: Gerhardt P, Murray RGE, Wood WA, Krieg NR (editors). 791 Pages, Numerous Figures and Tables. Washington, DC: American Society for Microbiology; 1994.

34. Gordon RE, Barnett DA, Handerhan JE, Pang CHN. Nocardia coeliaca, Nocardia autotrophica, and the Nocardin strain. Int J Syst Bacteriol 1974:24:54-63.

35. Groth I, Schütze B, Boettcher T, Pullen CB, Rodriguez C et al. Kitasatospora putterlickiae sp. nov., isolated from rhizosphere soil, transfer of Streptomyces kifunensis to the genus Kitasatospora as Kitasatospora kifunensis comb. nov., and emended description of Streptomyces aureofaciens Duggar 1948. Int J Syst Evol Microbiol 2003:53:2033-40

36. Hasegawa T, Takizawa M, Tanida S. A rapid analysis for chemical grouping of aerobic actinomycetes. J Gen Appl Microbiol 1983;29:319-322.

37. Schumann P. Peptidoglycan structure. Methods Microbiol 2011:38:101-129.

38. Minnikin DE, Alshamaony L, Goodfellow M. Differentiation of Mycobacterium, Nocardia, and related taxa by thin-layer chromatographic analysis of whole-organism methanolysates. J Gen Microbiol 1975;88:200-204.

39. Collins MD, Pirouz T, Goodfellow M, Minnikin DE. Distribution of menaquinones in actinomycetes and corynebacteria. J Gen Microbiol 1977;100:221-230.

40. Wink J, Schumann P, Atasayar E, Klenk HP, Zaburannyi N et al. 'Streptomyces caelicus', an antibiotic-producing species of the genus Streptomyces, and Streptomyces canchipurensis Li et al. 2015 are later heterotypic synonyms of Streptomyces muensis Ningthoujam et al. 2014. Int J Syst Evol Microbiol 2017;67:548-556.

41. Minnikin DE, Collins MD, Goodfellow M. Fatty acid and polar lipid composition in the classification of Cellulomonas, Oerskovia and related taxa. J Appl Microbiol 1979;47:87-95.

42. Collins MD, Jones D. Lipids in the classification and identification of coryneform bacteria containing peptidoglycans based on 2 , 4-diaminobutyric acid. J Appl Microbiol 1980;48:459-470.

43. DMSZ. DMSZ service: analysis of cellular fatty acids: available from. https://www.dsmz.de/services/services-microorganisms/ identification/analysis-of-cellular-fatty-acids.html 